\title{
What even is 'Climate'?
}

Oliver Bothe ${ }^{1}$

${ }^{1}$ Helmholtz-Zentrum Geesthacht, Institute of Coastal Research, Max-Planck-Strasse 1, 21502, Geesthacht, Germany

Correspondence: Oliver Bothe (ol.bothe@gmail.com, oliver.bothe@hzg.de)

Abstract. Although the concept of climate is easy to understand, there is not any uncontroversial definition of it. Most definitions fall back to the simple formulation that 'climate is the statistics of weather'. Recent attempts at a definition called versions of this saying vague. Climate is policy-relevant, and discussions on climate and climate change benefit from clarity on the topic. Beyond the policy relevance a definition should also be valid for scientific purposes and for individual views. It has to account for a general concept and individual instances of climate. Here, I try to highlight why the flexibility and the immediacy of the colloquial definition fit the topic. This defence shifts the lack of a clear definition towards the term 'weather' and the time-scales separating weather and climate.

\section{Introduction}

"Climate is what you expect, weather is what you get" (e.g., Geographical Association and London Geographical Institute, 1902; Lorenz, unpublished). Or: "Climate is the statistics of weather" (e.g., McBean et al., 1992; Easterling et al., 1999; Farmer, 2014; Molua and Lambi, 2007; von Storch, 2004; Roe and O'Neal, 2009; Roe, 2009). Public discourse and scientific literature frequently use versions of these colloquial sayings.

It is easy to agree with such statements as climate and weather have meaning for many or even most people. Everybody experiences weather and the notion of different climates is likely common. This is despite that the concepts of 'climate' and 'weather' developed over centuries in different cultural contexts (Heymann, 2010; Stehr and von Storch, 2000, 1998; Barnes, 1921; Mahony and Endfield, 2018).

Rudiak-Gould (2012) warns that communication about climate often requires a translation, whether this translation is cultural or linguistical. In communicating, scientists and citizens, politicians and non-governmental organisations, Europeans and, e.g., Marshallese have to translate their views on the climate to be understood. Translations of climate in different languages may then have implications, which the original use did not intend (Rudiak-Gould, 2012). For example, the translation may refer to other environmental issues or even the sociocultural system.

The historical development of the concept of 'climate' but also the contemporary discussions of climate include multiple perspectives on the concept. There is a cultural view on climate, best captured by Hulme (2016, compare also Tol, 2018). Such cultural views possibly further differ by whether they include the anthroposphere in the climate system or see the climate system as separate from the human domain. There are classical, mostly descriptive views on climates from the ancient Greeks to 20th century geography (e.g., Heymann, 2010; Hulme et al., 2009; Hulme, 2016; Heymann and Achermann, 2018; 
Mauelshagen, 2018; Fleming and Jankovic, 2011). There are the diverse, but generally reductionist views by the diverse communities of climate science. These include purely statistical perspectives either in terms of time intervals or ensembles, the view of climate as an attractor, or combined statistical-physical definitions (compare, e.g., Schneider and Dickinson, 1974; Leith, 1978; Lawhead, 2015; Conradie, 2015; Katzav and Parker, 2018). Some of these take a regional perspective, some consider a global climate (Mahony, 2017; Heymann, 2018). Many of these perspectives at least imply variations of the colloquial saying although they may refer to different aspects of climate. Fleming (2015) calls 'climate' a "shape-shifting" idea "whose meaning [may change] faster than the climate itself".

Since climate is a topic of policies, and discussions on policy benefit from clarity of the topic, multiple authors expressed concerns that the lack of a clear definition impedes conversations on climate and, in turn, policy making (e.g., Werndl, 2015; Todorov, 1986; Bryson, 1997; Lorenz, unpublished; Daron, 2012). One could argue we do not need a thorough definition, because people understand the intentions already without it - at least in the western world. Some may see the question of how to best or correctly define 'climate' as purely academic or philosophic. If even the history of climate governance by Gupta (2014) does not need to define climate, maybe conversations are clear enough? However, one has to keep in mind the implications of the work of Rudiak-Gould (2012).

The referenced concerns (e.g., Werndl, 2015; Todorov, 1986; Bryson, 1997; Lorenz, unpublished; Daron, 2012) suggest there is a common sense assumption regarding climate that discussions need agreement on what is discussed. Werndl (2015) points to the problems that may arise from a lack of clarity in talking about climate. Depending on their definition of 'climate', correspondents may come to differing conclusions about the seriousness of climatic changes. The thing called 'climate' in a conversation even may not be climate at all. Daron (2012) notes this as well.

However, there are no obvious examples where the lack of a definition hindered science or policy making. Of relevance may be the anecdotal evidence by Miller and Edwards (2001). They describe the frustration felt by a journalist and a science advisor, while both tried to agree whether they wanted to talk about local climate or global climate. The exchange betweeen Todorov (1986) and Quinlan (1986) also highlights how two authors first have to negotiate about the terms they use.

The contrast between local and global perspectives indeed was a problem in early multilateral climate negotiations according 25 to Miller (2004). On the other hand Heymann (2018) and Hulme (2016) suggest that the ever more global view on climate reduced the relevance of the discussions for local and regional communities. Tourangeau et al. (2019) emphasize that for stakeholders who depend on the weather, the concepts of weather and climate are interdependent. Specifying what is understood by climate may benefit communication in such cases.

Cass (2017) details, how the climate change problem had to be defined to become accessible for politics and Bodansky (1995) emphasizes that binding policies require agreement among discussants. To form an opinion about policies one has to understand their benefits and negative sides (Freeman, 2018, https://medium.com/wintoncentre/facts-risks-and-emotions-dc9db134757c). In turn, this probably also requires agreement on the topic in question among those discussing the policy.

It is interesting to note that much of the literature on philosophy and history of climate science does not specify what the authors mean by using the term 'climate'. At best, they refer to variations of the common saying (e.g., Parker, 2014). For example, neither Parker (2006) nor Winsberg (2010) nor Petersen (2000) state what they understand by climate. Even 
Winsberg (2018) does not state this in his "Philosophy and Climate Science". Much of this literature focuses on practices of climate science like observations, modelling, or predictions.

Similarly, much of the collection by Heymann et al. (2017) concentrates on the use of prediction in atmospheric and climate sciences without specifying what climate refers to. Only few chapters of Heymann et al. (2017), e.g., Martin-Nielsen (2017)

5 and Mahony (2017), partially do address this question. These consider changes in scientific views on climate in the mid-20th century and a recently renewed focus on regional climates respectively.

On the other hand, Edwards (2010) introduces a number of perspectives on climate throughout his book and traces the evolution of the term. Core to his view on climate appears to be that "Climate is essentially the history of weather, averaged over time" (Edwards, 2010).

The absence of a clear definition of climate is at the heart of the considerations of Katzav and Parker (2018), who point to open questions of interest for the philosophy of climate science.

\subsection{Definitions of climate}

We use the term 'climate' in various contexts that refer to different temporal and/or spatial scales. 'Climate' has colloquial, scientific, philosophical, and political meanings. Already in this introduction, the use of 'climate' and climate may confuse. One refers to the word and the concept, the other to its realisation. We can define 'climate' or clarify what we generally mean by 'climate' from any of the perspectives mentioned. We can do this conceptually rigorously or with a view on everyday applications or with a focus on the science of the earth system. Here, I try to consider the term 'climate' and its common definition from a more or less everyday-perspective.

The aim of this manuscript is not to provide a new definition of 'climate'. It is simply to clarify or, if one wants to put it this way, defend that the classical sayings like "climate is what on an average we expect, weather is what we actually get" (Geographical Association and London Geographical Institute, 1902) appropriately capture the concept. In doing so, I do not aim at a comprehensive literature review. I recommend Conradie (2015) and Hulme (2016) as starting points for delving into the literature of what is 'climate' even—although these neither are comprehensive.

In the everyday sense, a definition of 'climate' has to account for scientific and policy purposes but also for individual views.

25 It should allow for classical climate classification (Köppen, 2011; Farmer and Cook, 2013; Willett, 1931; Barry, 2013) and modern perspectives and the development from the former to the latter (Heymann, 2009).

It is important to distinguish between the template definition of 'climate', which represents the concept, and the instances of climate, that people deal with. The colloquial formulation represents the concept validly but springs from individuals' views of their specific instances. Generally, public discussions mostly deal with instances. Therefore one needs to rigorously specify the instance of current interest. If communicators, discussants, educators, politicians, citizens, agree on the general concept they additionally have to discuss about what instance of climate they want to speak.

Naturally one turns to the International Panel on Climate Change (IPCC) for a definition of 'climate'. Their fifth Assessment Report (IPCC, 2013) takes the view that 
"Climate in a narrow sense is usually defined as the average weather, or more rigorously, as the statistical description in terms of the mean and variability of relevant quantities over a period of time ranging from months to thousands or millions of years. The classical period for averaging these variables is 30 years, as defined by the World Meteorological Organization. The relevant quantities are most often surface variables such as temperature, precipitation and wind. Climate in a wider sense is the state, including a statistical description, of the climate system."

Climate in both senses are instances of a common template. The American Meteorological Society (AMS, 2016b) describes climate in a similar way (last modified in the year 2012) as

"the slowly varying aspects of the atmosphere-hydrosphere-land surface system. It is typically characterized in terms of suitable averages of the climate system over periods of a month or more, taking into consideration the variability in time of these averaged quantities..."

As a sidenote concerning the observable climate, Lovejoy and colleagues suggest to replace the dichotomy in terms of temporal variability between weather and climate with a weather-macroweather-climate trichotomy (e.g., Lovejoy, 2013; Lovejoy and Schertzer, 2013; Lovejoy et al., 2013). The expected state is the macroweather and climate is its evolution at longer timescales. Combining this with the AMS definition, AMS-climate becomes Lovejoy-macroweather, and Lovejoy-climate is the AMS's "variability in time of these averaged quantities".

Many authors presented their views on the concept of 'climate'. Todorov noted in 1986 a lack of "agreement among climatologists on the definition of the term climate" (Todorov, 1986). A similar notion motivated Bryson's essay on climatology (Bryson, 1997). He distinguishes between Climate (upper-case) and climate (lower-case). In his definition Climate is "the thermodynamic/hydrodynamic status of the global boundary conditions that determine the concurrent array of weather patterns." Lower-case climate is "the statistical characteristics of the weather assemblage at various places, or "typical weather" ". Lower-case climate agrees with the common dictum. Similar views focussing on the atmosphere are common in the German language literature (e.g., Hann, 1883; Kraus, 1984; Wanner, 1986). On the other hand, the opening of von Storch and Zwiers (2001) emphasizes the origins of climatology by stating

"Climatology was originally a sub-discipline of geography, and ... [d] escription of the climate consisted primarily of estimates of its mean state and estimates of its variability about that state... The paradigm of climate research evolved ... towards an understanding of the dynamics of climate... Statistics plays an important role in this new paradigm.”

According to them, 'climate' is a description of the climate system in terms of statistics as also the IPCC writes (IPCC, 2013). The descriptive climatology and the physical and chemical concepts of the atmospheric sciences may provide different perpectives for a definition.

Heymann (2009) details how the term 'climate' and the methods of scientists studying it changed from a descriptive approach to a physical and mathematical one. This relates to the point of Hulme et al. (2009) how climate and expectations of it are not 
purely scientific but also social constructs. Similarly, Heymann (2010) emphasizes the cultural contexts of different views on climate. See also Hulme (2016) for a detailed discussion of the relations between 'culture' and 'climate'. A concept of 'climate' has to allow for all these culturally conditioned instances. A definition of the observable climate may be easy, but it is only one instance.

5 The idea of a culturally constructed view on 'climate' refers on the one hand to the fact, that scientists' understanding of the world influences their view of what they consider to be climate. There are the perspectives of greek philosophers; for example, Ptolemy took a solely astronomical perspective on climate (Frisinger, 1973). There was also Humboldt, who viewed 'climate' as a geographically localised property and as something that directly affects humans (Heymann, 2009). The view on 'climate' developed towards a more dynamical understanding in the middle of the 20th century. Throughout history, new observational techniques resulted in different constructs of 'climate' (Heymann, 2010).

On the other hand, any societal actor may use a definition of 'climate' that possibly differs from a scholar's. Stehr and von Storch (1995) mention the example of famine in 14th century England that the church interpreted as climatic change and that people's atonement could revert. Societies define their own view on climate. Following Hulme et al. (2009), geographic locations, cultures, and traditions influence individual and collective definitions of 'climate'. 'Climate' is something that we remember (e.g., Hall and Endfield, 2016; Hulme, 2016).

If someone asks about the implications of climate change they refer to their specific notions of the current climate. These will differ from the notions of their neighbour as both notions will differ from an "official" estimate of the climate. All three estimates possibly align with the concept. The rigor in the discussion has to apply to the agreement of the discussants on the instance under consideration. These ambiguities in talking about 'climate' highlight the need for clear statements what one means when one uses the term 'climate'.

When talking about definitions of 'climate' or instances of climate, the literature, and I as well, mainly take a North American and European look on the topic. In a sense, we impose our perspective on the topic (compare, e.g., Hulme, 2016; Mahony and Endfield, 2018; Rudiak-Gould, 2012). Cultural views who may translate to 'climate' may originally include the society or other elements of the environment.

Coming back to the common saying that "climate is the statistics of weather", Werndl (2015) calls the IPCC-version (IPCC, 2013) of this dictum vague. This perceived vagueness and the lack of an agreed on definition led her to systematically approach a rigorous definition. She formulates five conditions on a definition of 'climate':

- There have to be empirical applications, e.g., if there are observations they have to provide the climate.

- If time-periods differ uncontroversially in their climate, the definition has to account for this.

- The definition should apply to climates from the past to the future including the present.

- The definition has to be mathematically well-defined.

- She also includes the following desired property of a definition: climate should not depend on our knowledge, i.e. saying what the climate was and whether it will change should be independent of the quality of our knowledge. 
In turn, Werndl (2015) and Frigg et al. (2015) arrive at preferred definitions, which state that 'climate' is the distribution of climate variables “over time for regimes of varying external conditions”. This is similar to Bryson's view (Bryson, 1997). These authors and further colleagues still conclude in Bradley et al. (unpublished) that "defining climate is nontrivial and there is no generally accepted or uncontroversial definition of climate".

5 I would add a sixth 'desideratum', which may be incompatible with Werndl's. The definition has to be continuously applicable (compare, Mitchell, 1976). If I take overlapping time periods, I obtain different instances of climate. These may be virtually identical or they may differ according to accepted criteria. 'Climate' evolves gradually.

As different as the above descriptions of climate are they do not generally contradict the view that "climate is the statistics of weather". Some see the dictum as vague and unspecific (Werndl, 2015; Frigg et al., 2015), I would call it intuitive, simple, and most importantly flexible. It allows for the variety of instances of the concept which scientists and non-scientists commonly call 'climate'. As Lucarini (2002) emphasizes, the subjectivity and ambiguity of definitions of climate are due to the fact that the definition itself depends on the current focus of the research or policy.

By shortly discussing what one may mean by 'weather' and reflecting on the components of the classical notions of climate, I am going to make the point that "Climate as the statistics of weather" is an appropriate definition of the concept of 'climate'.

15 Furthermore, it is usually clear enough as a definition. Problems mainly arise in stating the instance of climate one speaks about.

Bryson (1997), the IPCC (2013), the AMS (American Meteorological Society, 2016b), von Storch and Zwiers (2001), Wanner (1986), Kutzbach (1976), Leith (1978), Schneider and Dickinson (1974), and many more (compare, e.g., in Conradie, 2015), all present slight variations on the colloquial view on climate. These emphasize Todorov's point that everybody talks about climate but there remains ambiguity about the term (Todorov, 1986). If we for the moment take 'climate' as a term that subsumes information of weather, we need to first consider the term 'weather'.

\section{On 'weather'}

Weather is easier to describe than climate and thus also better defined. However, as hopefully becomes clear in the following, it is a major problem in defending the colloquial definition of 'climate'. My defence may stretch the definition of weather or shift the gap in the definitions towards the term weather.

What is weather? How do I experience weather personally right now? It is grey, wet and cold but calm. Temperature is relatively low, it drizzles and there is a closed cloud cover but no wind. Yesterday's weather was similar, but there was more wind and more rain.

If I were on a research vessel, I would also be interested in the wave height. Is the wave height weather? 


\subsection{What is weather?}

There is the term 'ocean weather'. There is also the science of space weather which refers mainly to the conditions and influences of the Sun, the solar wind, and similar contributors on the conditions in the solar system. It often focusses on the space surrounding the Earth (Bothmer and Daglis, 2007; Moldwin, 2008; Baker, 2002).

Geology uses the term 'Weathering' to describe mechanical, chemical, or biological influences on the earth's surface but it has to be distinguished from 'Erosion' (American Meteorological Society, 2016d). Weathering may also have an effect on climate (e.g., Köhler et al., 2010).

Common to all these usages of the root "weather" are variations, mostly referring to atmospheric processes but also their interaction with other compartments of the earth system and not just their action on these components. In the case of space weather 'variations' and 'interactions' are still considered but the 'atmospheric' component is missing. However, 'weather' may also depend on influences from space weather.

The American Meteorological Society gives the following definition of 'weather' (American Meteorological Society, 2016c): "The state of the atmosphere, mainly with respect to its effects upon life and human activities.... weather consists of the shortterm (minutes to days) variations in the atmosphere. ..." The AMS's definition of an atmosphere reads (American Meteoro-

15 logical Society, 2016a): “A gaseous envelope gravitationally bound to a celestial body...” The AMS's definition of 'weather' emphasizes the minutes to days scale of the variations of an atmosphere and how life, humans, a celestial body, e.g., the planet Earth experience them.

If I want to take 'climate' as the statistics of 'weather', as noted in the introduction, I either have to take 'weather' to extend beyond an atmosphere or to refine 'climate' to refer only to atmospheres. Is the latter acceptable?

Some authors indeed try to confine climate to the atmosphere while emphasizing that understanding the atmosphere requires to consider its interactions with other compartments of the climate or earth system (e.g., Kraus, 1984; Wanner, 1986). Thus, my simple answer is, that it is not acceptable to view 'climate' as something solely atmospheric. 'Climate' includes descriptions of quantities of the various compartments of the climate system (IPCC, 2013; American Meteorological Society, 2016b). If this is our first order view of 'climate', these are the statistics of 'weather' and, then, these statistics go beyond the atmosphere. Then, what is the 'weather' whose statistics are 'climate'?

Various cited definitions of 'climate' and 'weather' use the word 'state' (e.g., American Meteorological Society, 2016c), which may be of relevance in deciding what contributes to weather. The Oxford Dictionary of English writes a state is "the particular condition that someone or something is in at a specific time" (Stevenson, 2010). Noteworthy is the wiktionary's way of putting how physics defines a state (Wiktionary, 2016): "A complete description of a system, consisting of parameters that determine all properties of the system". Then the conditions of an atmosphere at a specific time are weather. Weather completely describes the 'system'. Obviously it is practically impossible to describe it completely but the concept of 'weather' encompasses everything that would be needed to describe the system. Does this include external, non-atmospheric dependencies or does it exclude these? 
An important part of the AMS's definition of 'weather' (American Meteorological Society, 2016c) is the experience of the variations. We experience weather instantaneous. Perceptions of weather relate to temperature, humidity, wetness, cloudiness, sunshine or no sunshine, and how windy it is. Experiences of weather also may include, e.g., its influence on the biosphere, how it influences health, and how it influences flora. Blooming of trees and flowers, budding and bursting, and pollen counts all depend on weather and are manifestations of weather. Weather influences the plankton by wind and incoming radiation and plankton influences the weather due to the flux of gases produced by plankton to the atmosphere (Kloster et al., 2006; Krüger and Graß1, 2011).

The amount of atmospheric particulate matter is not classically seen as weather, but 'weather' may encompass it. Transport of sand or dust may be components of weather. Weather influences soil moisture which in turn may influence weather up to seasonal time-scales. Is a long heat-wave still weather? Does a flood event qualify as weather? People may consider a flooded basement or field as weather, they may regard smog, or Sahara-dust on their cars as weather.

If one includes a set of external dependencies in the state, 'weather' extends beyond the atmosphere. Which of Earth's climate system compartments influence its atmosphere and its weather? The biosphere influences the weather, e.g., by transpiration and by its potential to emit cloud condensation nuclei. The cryosphere influences the weather by, e.g., the extent of its glaciers and presence and amount of sea-ice. The hydrosphere's components of oceans, surface moisture, and flow of surface-water affect the moisture-budget and the energy of the atmosphere. The lithosphere and not only the pedosphere can exert similar influences as hydrosphere and cryosphere. Some of these processes are slow, some are fast. Which processes are reasonably seen as part of weather and which only influence our expectations of weather, i.e., climate?

The German Weather Service DWD considers the following as external to their weather forecast model (DWD, 2016a, b): ice-free ocean-surface temperature, sea-ice extent, land-sea mask, orography, surface type, albedo, land-use, vegetationproperties, and the spatial and temporal distribution of aerosols and trace gases. Here, external means they are prescribed properties and not internally calculated. Many of these variables are slow varying aspects that provide boundary conditions on at least seasonal time-scales.

On the other hand, land-surface-temperature, land-surface liquid-water- and ice-content, the surface-snow properties, and the thickness and surface-temperature of sea-ice are internal, i.e. predicted in the DWD's forecast model (DWD, 2016a, b). These, in turn, are generally fast changing properties that directly influence and are influenced by local weather variability.

In summarising, the concept of 'weather' is applicable to bodies with atmospheres and their representations. It involves those variables determining its state at a moment in time. Quantities influencing the state can be external to the atmosphere.

There is another problem besides what counts as 'weather'. If 'weather' refers to minute to day variability, and if 'climate', as the AMS writes, is the statistics of at least monthly averages of (earth) system variables (American Meteorological Society, 2016b), what is the monthly average of the (sub-)daily weather? More generally, what are time-scales of weather?

\subsection{Time-scales of weather}

If, for Earth, 'weather' takes place from minutes to days (American Meteorological Society, 2016c) and, assuming, the shortest climate time-scale is monthly (American Meteorological Society, 2016b), a conceptual definition of the transition and of the 
temporal difference between 'weather' and 'climate' becomes necessary. This may sound trivial but researchers and climate change activists regularly refer to interannual variability in weather and climate parameters as weather in the sense that there is not a forced response but just different weather situations from year to year. On the other hand, a multi-day mean is one simple statistic of atmospheric variations on (sub-)daily time-scales. One could see such a statistic of weather as an instance of 'climate'. Nevertheless it is usually not considered as 'climate'. The conceptual transition is not instantly clear.

The difficulty in a conceptual transition from 'weather' to 'climate' may originate from the different scientific histories of the terms. Weather is a concept of meteorology—or atmospheric physics. Climate is a descriptive concept. Climate was used to classify, weather described a dynamic evolution (e.g., Heymann, 2009, 2010).

The IPCC (2013) uses the "spatial and temporal" scale of "individual weather events" to separate climate variability from weather. This view originates in the classical scale diagrams of meteorology which plot typcial spatial against typical temporal scales (e.g., Orlanski, 1975; Daley, 1993; Cullen and Brown, 2009; Kraus, 2007; Stull, 2012; Dickinson, 1988; Norbury and Roulstone, 2002; Donner et al., 2011; Mölders and Kramm, 2014; Laing and Evans, 2011; Dolaptchiev and Klein, 2013; Klein, 2010). See also the works by Kutzbach (1976), Mitchell (1976), Kraus (1984), Clark (1985), and Wanner (1986). Insofar as these diagrams consider a climate time-scale the transition from weather to climate encompasses phenomena like the intraseasonal Madden Julian Oscillation (Zhang, 2005), the seasonal cycle, and the interannual El Niño/Southern Oscillation (Philander, 1989; Diaz and Markgraf, 2000).

One may formulate the transition dependent on the system and the process under consideration as the scale at which the predictability of an instance of 'weather' reaches its limit. The transition occurs at time-scales for which the spectra have white characteristics, where there is no memory. Indeed this is comparable to Lovejoy's view on the transition from weather to macroweather (Lovejoy, 2013).

The transition occurs when our expectation of the properties becomes a better estimate than a deterministic forecast or as good an estimate as a probabilistic forecast. Then the upper limit of 'weather' is the time-scale at which the boundary conditions become at least as important as the initial conditions. These formulations are general and do not only apply for certain instances, e.g., weather on Earth.

Then, 'weather' are variations on a certain time-scale of variables that describe the state of a body with an atmosphere. They depend on certain aspects of a system. This system can be described by fluid dynamics and thermodynamics. The 'climate' time-scale begins and the 'weather' time-scale ends for a certain variable where our description of the system transitions from being that of a quasi-instantaneous state to that of probabilities of states over time. Related versions of this view invoke weather predictability, memory, scaling, decorrelation times, or persistence (e.g., Lorenz, unpublished, 1969a, b, 1973; Hosking, 1984; Fraedrich, 1987; Fraedrich and Ziehmann-Schlumbohm, 1994; von Storch, 1999; Baldwin et al., 2003; Fraedrich and Blender, 2003; Lovejoy, 2013). That is, the duration of the dominance of the initial conditions on this state limits the time-scales of 'weather'. 


\section{On 'climate'}

If the above describes 'weather', how do we describe 'climate'? I noted that if I mean 'climate' to be the statistics of 'weather', 'weather' has to involve more than the atmosphere. This is warranted not only because the boundary conditions are relevant parts describing the state of the atmosphere, i.e. 'weather', but also because people experience phenomena involving other

5 (earth) system compartments as weather.

The term 'climate' has been a classification of convenience from the beginning (compare Heymann, 2010; Stehr and von Storch, 2000, 1998; Barnes, 1921; Fleming and Jankovic, 2011; Fleming, 2015; Mahony and Endfield, 2018; Hulme, 2016). It encapsulates observations of one's surroundings and helps to sort them and to compare them to other locations. It is an expression of individuals' experience and expectations of 'weather' including various earth system compartments. As such an individual's view, the roots of the classical use of the term lie more in single instances of climates than in a template of 'climate', i.e., the concept. On the other hand the simple formulation is so general that it indeed may validly describe the concept.

Bryson, von Storch and Zwiers, the IPCC, but also others offer potentially complementary views of what 'climate' is. It is a "state" of the "climate system" (IPCC, 2013) described by "estimates of its mean ... and estimates of its variability" (von

15 Storch and Zwiers, 2001). "[T]he thermodynamic/hydrodynamic status" of the "boundary conditions determine[s]" (Bryson, 1997) the possible occurrences of this 'state'.

\subsection{Instances of 'climate'}

It is helpful to approach a view of the template of 'climate' from instances of climate. 'Climate' in the classical sense is a description of the properties of a certain location in space and time. It allows to compare these properties between different places (e.g., Hamburg and Damaskus, or Minneapolis and Chongqing) and/or different time periods (e.g., the Middle Pleistocene and the early Holocene, or Roman times with the twentieth century) and/or different sources of data (e.g., simulations and observations, or different compilations of observations).

Climate classifications have used the meridional zones of the globe, the prevalent air masses, the aridity, or vegetation. Climate may refer to your garden, the city of Aleppo, Worcestershire, Brasil, Europe, or a celestial body with an atmosphere. The concept of 'climate' has to incorporate the climate at single locations as well as the climate at, e.g., planetary scales. It has to allow for climate at the surface, in the upper atmosphere, and in the ocean. One may want to describe the summer climate, the climate of the late 20th century, or the climate of the Pliocene. The focus may be local or global. I may consider a season in a short 20 year period or the average over millions of years. Any definition of what the term 'climate' constitutes has to serve the cultural purpose besides complying with our modern usage in studying the earth's current climate, past changes in the climate system, and future projected changes due to, e.g., anthropogenic combustion of fossil fuels.

All these are valid instances of the concept of 'climate'. No individual instance defines 'climate'. Describing instances as well as the concept requires clarity on a number of descriptors of climate like the terms 'variable', 'data', 'statistic', 'uncertainty', 
and 'ensembles', as well as the location and time of an instance, and the general ideas of climate forcings, climate change and climate variability.

'Climate' variables are potentially multiple properties or just a single property of the instance of climate in question. Climate may refer to surface temperature alone or a large set of variables like temperature, precipitation, cloudiness, incoming solar radiation, snow cover, and the seasonality of these and more variables. Variables are not necessarily basic observables but may also derive from multiple other variables or one variable at different locations.

'Climate' data are not necessarily real weather observations. They may come from a model-simulation or may be inferred from proxies, i.e. from approximating representations in regions or times when there are no direct observations. Here, model does not exclusively refer to sophisticated earth system models but simply to a representation of a system that is able to reflect the behavior and evolution of the system, e.g., a time-series model. Indeed, observations are still just representations. They are the values from a model that translates recordings by a sensor of environmental conditions into data that one can interpret in terms of weather or climate variables (compare, e.g., Evans et al., 2013).

'Statistics' are the results of analysing and interpreting the data (Dodge, 2006). That is, we do Statistics. We do so by calculating summary values, i.e. statistics. Each such statistic (Dodge, 2006) helps to describe the data. Common instances of statistics are expectations of the mean of a certain data or expectations of the deviation from the mean. In a first step the interest is often an estimate of the distribution of the data, which may be achieved by estimating these expectations if the data has certain properties. In terms of climate, the interest is in the full and potentially multivariate probability distribution which likely requires other estimates beyond simple measures of mean and deviation from the mean. The statistics can become much more complex.

Uncertainty is important for a definition of 'climate' to be useful for research. Each data point and each statistic is an uncertain, imperfect estimate. This holds even when it is not possible to quantify the uncertainty or when one only can acknowledge it implicitly. Instances of climate are unlikely perfect descriptions but uncertain approximations. This is obvious for real-world observations of properties of past climates or the current climate. Only uncertainty allows for models of climate which are by definition imprecise and uncertain. Uncertainty must be allowed for the boundary conditions, for external influences, and 25 for the internal processes in the instance of climate. Each estimate may have a specific uncertainty. Besides these uncertain instances, it has to be possible to derive an instance from the concept that is identical with the concept and only relies on abstract definitions.

Ensembles of data are common in climate research. A definition only allows for an ensemble view of different observational data sets or model simulations if it also endorses uncertainty. Then it is possible to incorporate different estimates of the same property in an instance of climate (compare, e.g., Morice et al., 2012; Donat et al., 2014; Cahill et al., 2015; Jones, 2016; Rauser et al., 2015; Swart et al., 2015).

Space and time localise the instance, i.e., the part of a system of interest (compare, e.g., Kraus, 1984). Data describes certain properties of the system dependent on location, i.e. in all three dimensions, and time. The spatial localisation may narrowly define positions in latitude and longitude as well as in the vertical. It may mean a spatial summarizing description for a city, a 
county, a country, a continent, the globe. The spatial domain may be one location or an average. Local or global are the lower and upper limits of the spatial domain.

Knowledge about the past becomes temporarily coarser resolved the further one looks back. Thus, it may be relevant to speak of the climate of the late Eocene and thereby classify climate over a time-period of millions of years, of the climate of a

5 couple of centuries in the middle ages, or of the climate of a reference period of three well observed decades in the late 20th century. "Mean climate" may even refer to shorter periods to highlight short term variations which are thought to be not just weather but a variation or disturbance of interest of the instance of climate in question.

Such time-frames for one instance of climate may be longer or shorter dependent on the properties of the system. Climate on Mars or Jupiter may involve different time-scales. The age of the celestial body is the upper temporal limit. The lower temporal limit has to allow defining statistics and signifies the shift from a state-estimate mainly determined by its initial values, i.e. 'weather', to an uncertain expectation of the state mainly specified by its boundary conditions including further external influences.

Statistics concerning climate often refer to estimates for a time period, i.e. our data is collected over this period, or to estimates over an ensemble of copies of the system of interest (compare,e.g., Leith, 1978; Conradie, 2015). The period of time may be a collection of events rather than a consecutive sequence. The interest may be in the expected weather after a certain type of events in comparison to a climate without these events. It may be for a certain day in the year. There may also be instances when we calculate an estimate of climate over a spatial domain for one date, e.g., in the case of very low temporal resolutions of the data.

A climate is an estimate for a specific time-frame and a specific spatial scale. It varies in time and can change over time. If I change the specific period of interest I obtain another instance of climate.

\subsubsection{The Climate system}

Regarding instances of climate on our planet, variables of interest are part of the climate system or more comprehensively of the earth system. They are relevant and specific for the instance of interest at its location and on its time-scales. They describe a state which extends beyond atmospheric processes of purely meteorological interest. Summarising descriptions of the data give us the statistics of weather, e.g., the distributions of these variables. Our knowledge about these is uncertain.

Compartments of Earth's climate system are the atmosphere, the hydrosphere, the cryosphere, the biosphere, the lithosphere (IPCC, 2013). A description of the system's behavior may have to employ thermodynamics and fluid dynamics but also electromagnetism, rheology, and plasma physics besides statistics.

Then, 'climate' is a description of part of a system. It involves potentially multiple elements or just a single property of the 30 system in question. It may include elements of any individual compartment of the system or all together as long as they are relevant. Other parts and their variations may be seen as extrinsic of the climate but interact with it.

Such external influences and external boundary conditions are climate forcings. In certain instances, we may consider them internal, or they may originate from internal processes. 'Climate' depends on extrinsic influences, which are also varying in time (and potentially in space).

Version of doi:10.5194/gc-2018-11 that was rejected after one iteration of major revisions and submitted to EarthArXiv. 
The 'typical weather' (Bryson, 1997) or the possible weather for a certain location depends on the behavior of the system's compartments and external factors. Each compartment may depend on different external conditions but ideally it should be a common set for all.

Dependent on the specific temporal and spatial scales, the geographic specifics of the location or its surroundings differ.

5 The climate depends on its own geographic properties and its surroundings. For example, the distribution of land, ocean, and ice-sheets conditioned a different climate for the location of the city of Hamburg in Germany 10,000 and 20,000 years ago than today's configuration. Changes in land cover or land use alter the climate. The definition of 'climate' has to allow for such influencing factors.

For specific instances such factors may be considered intrinsic parts of the climate although some may indeed be external.

10 For example volcanic eruptions may change the composition of the atmosphere and thus change the expectations. Processes at the surface may change the atmospheric composition. Additional 'forcings' are changes in the path on which the celestial body of interest travels around its star or variations in the composition and power of the radiation from the star or cosmic rays reaching the celestial body. The human sphere also influences the climate system on Earth.

Climate variability and climate change describe the variations of the climate. Changes are usually considered slow and refer to detectable differences between climate statistics due to processes which we often but not necessarily may consider external to the climate system. Climate variability are faster variations within the reference time-frame which are usually thought to be intrinsic to the system and do not change the full multivariate distribution. That is, climate as the full probability distribution of certain properties in question is a distribution over the temporal variations at one or more locations dependent on extrinsic influences that are also varying and that influence the climate's evolution.

The climate is an estimate for a specific time-frame. It varies in time and can change over time with the time-frame. If I change the specific period of interest I obtain another instance of climate. Both distributions may be virtually identical or I may be able to detect that the probability of a certain event has clearly changed between both periods. Time-periods may overlap. It is important to allow for gradual changes. If statistics differ over a time period of interest from the distribution over a reference period, one speaks of change.

Regarding climate forcings, climate variability, and climate change, a slight excursion is in place. Werndl (2015) and Frigg et al. (2015) express concerns considering the robustness of classical views on climate to sudden shocks to the system. These authors define 'climate' and changes to it over different 'regimes' of external conditions.

This regime view accounts for the desired property of a definition that we can undoubtedly identify different climates. However, climate changes transiently, and defining 'climate' and its change for regimes excludes the possibility of gradual changes (compare also Leith, 1978). The regime view appears to only consider climate states in equilibrium. Furthermore, it is dubious, how observers can define the instance of climate directly after a sudden forcing shock.

There may not be a robust way to reconcile the wishes for a gradual definition and a definition that allows uncontroversially identifying different climates. However there may be a possible compromise. We have to assume that 'climate' also includes at least a relevant subset of forcings. If the forcing is part of the climate, e.g., volcanic eruptions, a very strong eruption can switch 'on' the already included forcing. Even if the maximum forcing amplitude occurs quickly, the time until it reaches 
its maximum can be described transiently and represents a large number of infinitesimal shock events. If a climate includes all potential shock events as on-off variables, then it also accounts for the instantaneous change as the external forcing state changes to on from its off-state. If our instance of climate did not previously include the climate forcing, it seems appropriate to assume that the spontaneous on-state of an extrinsic forcing itself changes the climate. The occurrence of the shock alters

5 the observed system.

Processes internal to an instance of the climate system result generally only in variability of an instance of climate. Processes external to the instance of the system can change our instance of climate. However, external influences may not result in identifiable changes, while certain internal processes may change the instance of climate under consideration. For the sake of defining 'climate', it may be necessary to include the external forcings in the instance of climate or at least consider any instance only with an associated instance of forcings. Both groups of properties vary gradually.

\section{Discussion and Concluding remarks}

Non-scientists and scientists alike often refer to climate in variations of the formulation "climate is what on an average we expect, weather is what we actually get" (Geographical Association and London Geographical Institute, 1902). Even attempts to define the term 'climate' often fall back to more sophisticated variations on this colloquial saying (e.g., Bryson, 1997). This suggests, such a "vague" definition serves quite well scientifically and in everyday situations.

In turn, climate scientists may be tempted to consider the search for a more rigorous definition of little value. However, as Katzav and Parker (2018) note the theories at the foundations of climate science are not as clearly stated as one would wish for-at least from but not confined to a philosophical perspective. Katzav and Parker (2018) highlight the questions what counts as part of the climate system, and how to describe climate states among other things. Their use of climate state is in parts equivalent to my use of climate, i.e. a climate state is a climate. Katzav and Parker (2018) distinguish between statistical and combined physical-statistical descriptions. Additionally they highlight the partly contrasting temporal and dynamical systems perspectives on climate (compare also, e.g., Conradie, 2015).

Similarly, climate scientists like Lorenz (unpublished), Bryson (1997), Todorov (1986), and Daron (2012) note the lack of a clear definition and imply that this may become problematic in communicating climate and in political discourses about climate. This concern appears to have motivated the work by Werndl (2015).

To paraphrase this concern: the lack of a robust definition is problematic as it at least can lead to confusion and thus loss of time, and at the worst can prevent agreement among discussants. A robust definition aims to clarify the concept. However, policy discussions and individual views generally refer to instances. Discussants have to agree on the instance they refer to in view of their diverse professional, linguistic, and cultural backgrounds. This also relates to the delineation of the climate system as Katzav and Parker (2018) note. Which parts of the system do the discussants consider to describe the instance of interest, and, politically, which parts are governable and which parts are off limits for policies (compare the discussions in Hulme, 2016). Indeed, culturally and linguistically words used for climate may include or exclude certain parts of the system before and after translation (e.g., Rudiak-Gould, 2012). Understanding and beliefs on climate change differ among societal actors 
and stakeholders. Then, communication benefits from clarifying the instance of climate. Put differently, tailoring messages for stakeholders (e.g. Prokopy et al., 2015; Tourangeau et al., 2019) also includes specifying the instance of climate of interest to the stakeholder.

One has to ask: have there been circumstances when and where the lack of a common definition impeded climate policies or 5 climate science? Indeed, there is no obvious case where the absence of a definition of the concept of 'climate' hampered politics or science. However, Daron (2012) asserts: "the definition of climate remains contested and has led to confusion in both the public and scientific discourse surrounding global warming and climate change”. Miller (2004) notes that considering climate only locally hindered international cooperation on topics of climate. This statement is in contrast to the considerations of Hulme (2016), who argues that the shift to a global climate perspective is problematic for potential policies since its metric "global temperature is not in fact a tractable object of policy. It is too abstract and underdetermined". Heymann (2018) diagnoses that a global perspective of climate loses view of the human dimension. Already Miller and Edwards (2001) realize that some criticise global climate perspectives as being not suitable for the needs of policy making and politics.

Clark (1985) and Wilbanks and Kates (1999) discuss the different potential domain scales of climate, its change and its impacts, and the relations between these different scales. The contrast between local, regional, and global instances of climate likely is going to become even more important with the emergence of plans for climate engineering applications (compare, e.g., Lo et al., 2018, , the blog-post by Kravitz, 2018, and the special issue of the journal Earth's Future at https://agupubs. onlinelibrary.wiley.com/doi/toc/10.1002/(ISSN)2328-4277.GEOENGIN1). Thus, while the lack of a definition of the concept may not have hampered politics, different assumptions on the instance of climate of interest may very well have lead to ineffective policy discussions.

My thoughts above tried to defend the common views of 'climate' as the statistics of 'weather', and 'climate' as expectations of what kind of 'weather' one is going to 'experience'. My chosen approach may ask the wrong question and one cannot conclusively define weather, climate, or at least their temporal dichotomy and terminological dependence. If that is the case, the differing origins of the terms and how the view of 'climate' evolved over time (Heymann, 2009) prevent a rigorous definition (compare also Conradie, 2015; Hulme, 2016; Edwards, 2010). That is, in this case, there is 'weather' with its traditional definiton (e.g., American Meteorological Society, 2016c), and there is the evolving concept and understanding of 'climate' which includes weather but extends beyond it.

Then, there would be on the one hand the colloquial 20th century view of both terms which contrasts expectations and experience. That is, 'weather' would be what we experience and 'climate' what we expect from the weather under certain conditions. As Kennedy writes on Twitter: "Practically speaking: weather's how you choose an outfit, climate's how you choose your wardrobe" (Kennedy, 2013). Both concepts would critically depend on the subjectivity of an individual or a social group and would be primarily social or cultural constructs. Hulme (2016) presents a thorough though not in all parts convincing portrayal of the idea of climate as an arrangement that allows humans and their culture to deal with the ever-changing weather.

On the other hand, there would be the earth-sciences' use of the terms. 'Weather' would be the concept of meteorology and atmospheric physics, and 'climate' would be a description in terms of statistics and physics of the interplay between the 
various earth system compartments as studied by geography, climatology, biogeochemistry, oceanography, but also atmospheric sciences and others.

Conversations and discussions on climate, whether political or everyday, then have to negotiate between different constructs. In the simplest case, these are the views on climate and weather of the individuals involved. An example of a conversation 5 on climate and weather that had to clarify the individual views on climate took place between Tol (2018) and Osborn (2018) on Twitter. Potentially even more complex would be negotiations between the evolving scientific view on climate and such individual or social constructs. Indeed, considering the policy relevance of climate, there may be a third perspective besides the colloquial and the research-oriented, the political. This likely has additional dependencies, e.g., the economic climate, besides being culturally informed.

My thoughts above led to the following: 'Climate' is not an instantaneous property but a summary over a certain time period. It involves the full statistical description, e.g., the distribution, of one or more properties of a system in question. The location of the system is on or represents part of an astronomical object with an atmosphere. The potentially multivariate distribution over the temporal variations at one or more spatial areas depends on 'extrinsic' forcings which are also varying in time and space. Any data in an instance of climate may be uncertain or may rely on different estimates of the same property.

This view or definition holds not only for an observed instance of climate but also for a model-representation, where a model is not necessarily a complex computational simulator but may also be a simple mathematical time-series model etc. 'Climate' is gradually applicable.

Thus, can I maintain my view that 'climate' is the statistics of 'weather'? A shorter version of the above reads:

Climate refers to properties on or representing parts of astronomical objects with atmospheres, which can experience weather. It is the time-varying uncertain summarising description of multiple properties of a representation of such a system for a specified spatial and temporal domain dependent on external factors varying in time and space.

If 'weather' is the description of the instantaneous time-varying state of an atmosphere and its interactions with the rest of the system, then 'climate' is validly described as the statistics of 'weather'. However, weather has to be qualified in this sense to allow my preferred definition.

These complicated formulations indeed reduce to versions of the colloquial saying. That is, the climate (of an astronomical object) describes statistically and physically the weather over certain domains of this body in space and time. It depends on all factors, which may affect this weather over space and time. Weather in this context, again, has to include other components of the system.

30 All these formulations are very unspecific. Indeed they are possibly even less specific than the colloquial "climate is the statistics of weather". However, I am convinced, a definition of the concept of 'climate' has to lack precision to accommodate the various potential perspectives on climate. The aim of this manuscript, however, was not to provide the umpteenth definition of climate. It was to clarify and thereby to defend, why the commonly held views on climate are indeed appropriate characterizations of 'climate'.

Version of doi:10.5194/gc-2018-11 that was rejected after one iteration of major revisions and submitted to EarthArXiv. 
If we assume that a lack of an accepted definition of 'climate' may hinder policies or even science, do my characterizations of 'climate' help to avoid misunderstandings? This is unlikely for the case of communication or policy making not least since both topics usually deal with instances of climate, e.g., the global climate, the climate of South America, of the Republic of Ghana, or of the town of Ust-Ilimsk. Instances do not only vary by location but also by time period, and cultural conditioning.

5 My considerations stress that in any exchange on climate, people and organisations have to be clear to which instance of a concept of 'climate' they refer to. This agreement on the instance of interest is important to avoid getting lost in translation (Rudiak-Gould, 2012), or to frustrate the discussants (Miller and Edwards, 2001). Whether it is necessary to ensure policy success remains unclear.

Howsoever one applies the term 'climate', it was, is, and will be an evolving concept (Heymann, 2009; Hulme, 2016; 10 Fleming and Jankovic, 2011; Fleming, 2015). It grows the larger our understanding becomes of the earth system and of the factors influencing it and its processes, e.g., weather.

Competing interests. I am not aware of any circumstances that might be seen as competing interests.

Acknowledgements. Comments by anonymous colleagues helped to improve the manuscript. I want to thank the two anonymous referees and the editor for their valuable comments and their support of this manuscript. 


\section{References}

American Meteorological Society: Atmosphere, http://glossary.ametsoc.org/wiki/Atmosphere, available at http://glossary.ametsoc.org/wiki/Atmosphere, accessed 11 February 2016, $2016 \mathrm{a}$.

American Meteorological Society: Climate, http://glossary.ametsoc.org/wiki/Climate, available at http://glossary.ametsoc.org/wiki/Climate, accessed 9 February 2016, 2016 b.

American Meteorological Society: Weather, http://glossary.ametsoc.org/wiki/Weather, available at http://glossary.ametsoc.org/wiki/Weather, accessed 11 February 2016, 2016c.

American Meteorological Society: Weathering, http://glossary.ametsoc.org/wiki/Weathering, available at http://glossary.ametsoc.org/wiki/Weathering, accessed 11 February 2016, 2016d.

10 Baker, D. N.: How to Cope with Space Weather, Science, 297, 1486-1487, https://doi.org/10.1126/science.1074956, 2002.

Baldwin, M. P., Stephenson, D. B., Thompson, D. W. J., Dunkerton, T. J., Charlton, A. J., and O’Neill, A.: Stratospheric Memory and Skill of Extended-Range Weather Forecasts, Science, 301, 636-640, https://doi.org/10.1126/science.1087143, 2003.

Barnes, H. E.: The Relation of Geography to the Writing and Interpretation of History, Journal of Geography, 20, 321-337, https://doi.org/10.1080/00221342108984090, 1921.

15 Barry, R. G.: A brief history of the terms climate and climatology, International Journal of Climatology, 33, 1317-1320, https://doi.org/10.1002/joc.3504, 2013.

Bodansky, D.: The Emerging Climate Change Regime, Annual Review of Energy and the Environment, 20, 425-461, https://doi.org/10.1146/annurev.eg.20.110195.002233, 1995.

Bothmer, V. and Daglis, I.: Space Weather: Physics and Effects, Springer Praxis Books / Environmental Sciences, Springer Berlin Heidelberg, https://books.google.de/books?id=N-U5XeWog0sC, 2007.

Bradley, R., Frigg, R., Steele, K., Thompson, E., and Werndl, C.: The Philosophy of Climate Science, http://romanfrigg.org/writings/phil_ climate.pdf, unpublished, available from http://romanfrigg.org/writings/phil_climate.pdf, last accessed 23 November 2018, unpublished.

Bryson, R. A.: The Paradigm of Climatology: An Essay, Bulletin of the American Meteorological Society, 78, 449-455, https://doi.org/10.1175/1520-0477(1997)078<0449:TPOCAE>2.0.CO;2, 1997.

Cahill, N., Rahmstorf, S., and Parnell, A. C.: Change points of global temperature, Environmental Research Letters, 10, 084002, https://doi.org/10.1088/1748-9326/10/8/084002, 2015.

Cass, L. R.: The Politics of Climate Change, vol. 1, Oxford University Press, https://doi.org/10.1093/acrefore/9780190846626.013.112, 2017.

Clark, W. C.: Scales of climate impacts, Climatic Change, 7, 5-27, https://doi.org/10.1007/BF00139438, 1985.

30 Conradie, W.: Conceptualising and quantifying the nonlinear, chaotic climate: implications for climate model experimental design, Ph.D. thesis, University of Cape Town, https://open.uct.ac.za/handle/11427/16527, 2015.

Cullen, M. and Brown, A.: Large eddy simulation of the atmosphere on various scales, Philosophical Transactions of the Royal Society of London A: Mathematical, Physical and Engineering Sciences, 367, 2947-2956, https://doi.org/10.1098/rsta.2008.0268, 2009.

Daley, R.: Atmospheric Data Analysis, Cambridge Atmospheric and Space Science Series, Cambridge University Press, https://books.google. de/books?id=RHM6pTMRTHwC, 1993.

Daron, J. D.: Examining the decision-relevance of climate model information for the insurance industry, Ph.D. thesis, The London School of Economics and Political Science, http://etheses.lse.ac.uk/380/, 2012.

Version of doi:10.5194/gc-2018-11 that was rejected after one iteration of major revisions and submitted to EarthArXiv 
Diaz, H. and Markgraf, V., eds.: El Niño and the Southern Oscillation: Multiscale Variability and Global and Regional Impacts, Cambridge University Press, https://books.google.de/books?id=JUOaO7zJx10C, 2000.

Dickinson, R. E.: Atmospheric Systems and Global Change, in: Scales and global change: spatial and temporal variability in biospheric and geospheric processes, edited by Rosswall, T., Woodmansee, R., and Risser, P., SCOPE report, Published on behalf of the Scientific Committee on Problems of the Environment (SCOPE) of the International Council of Scientific Unions (ICSU) by J. Wiley, http://www. scopenvironment.org/downloadpubs/scope35/, 1988.

Dodge, Y., ed.: The Oxford Dictionary of Statistical Terms, Oxford University Press, https://books.google.de/books?id=_OnjBgpuhWcC, 2006.

Dolaptchiev, S. I. and Klein, R.: A Multiscale Model for the Planetary and Synoptic Motions in the Atmosphere, Journal of the Atmospheric Sciences, 70, 2963-2981, https://doi.org/10.1175/JAS-D-12-0272.1, 10.1175/JAS-D-12-0272.1, 2013.

Donat, M. G., Sillmann, J., Wild, S., Alexander, L. V., Lippmann, T., and Zwiers, F. W.: Consistency of Temperature and Precipitation Extremes across Various Global Gridded In Situ and Reanalysis Datasets, Journal of Climate, 27, 5019-5035, https://doi.org/10.1175/JCLID-13-00405.1, 10.1175/JCLI-D-13-00405.1, 2014.

Donner, L., Schubert, W., and Somerville, R.: The Development of Atmospheric General Circulation Models: Complexity, Synthesis and Computation, Cambridge University Press, https://books.google.de/books?id=HTM0xMthjSQC, 2011.

DWD: Wetter und Klima - Deutscher Wetterdienst - Unsere Modellkette - Globalmodell ICON, http://www.dwd.de/DE/forschung/ wettervorhersage/num_modellierung/01_num_vorhersagemodelle/icon_beschreibung.html, in German, Online, accessed 12 February 2016, 2016a.

DWD: Wetter und Klima - Deutscher Wetterdienst - Externe Parameter, http://www.dwd.de/DE/forschung/wettervorhersage/num modellierung/01_num_vorhersagemodelle/01d_externe_parameter/externe_parameter_node.html, in German, Online, accessed 12 February 2016, 2016b.

Easterling, W. E., Stern, P. C., et al.: Making climate forecasts matter, National Academies Press, 1999.

Edwards, P. N.: A vast machine : computer models, climate data, and the politics of global warming, MIT Press, 2010.

Evans, M., Tolwinski-Ward, S., Thompson, D., and Anchukaitis, K.: Applications of proxy system modeling in high resolution paleoclimatology, Quaternary Science Reviews, 76, 16 - 28, https://doi.org/10.1016/j.quascirev.2013.05.024, 2013.

Farmer, G.: Modern Climate Change Science: An Overview of Today’s Climate Change Science, SpringerBriefs in Environmental Science, Springer International Publishing, https://books.google.de/books?id=2VIDBAAAQBAJ, 2014.

Farmer, G. and Cook, J.: Climate Change Science: A Modern Synthesis: Volume 1 - The Physical Climate, Climate Change Science: A Modern Synthesis, Springer Netherlands, https://books.google.de/books?id=tbtEAAAAQBAJ, 2013.

Fleming, J. R.: Weather and Climate as Shape-Shifting Nouns: Gordian Knots of Understanding and Prevision, History of Meteorology, 7, 577-586, http://www.iep.utm.edu/epistemo/, 2015.

Fleming, J. R. and Jankovic, V.: Revisiting Klima, Osiris, 26, 1-15, https://doi.org/10.1086/661262, 2011.

Fraedrich, K.: Estimating Weather and Climate Predictability on Attractors, Journal of the Atmospheric Sciences, 44, 722-728, https://doi.org/10.1175/1520-0469(1987)044<0722:EWACPO>2.0.CO;2, 1987.

Fraedrich, K. and Blender, R.: Scaling of atmosphere and ocean temperature correlations in observations and climate models, Physical Review Letters, 90, 108 501, 2003.

Fraedrich, K. and Ziehmann-Schlumbohm, C.: Predictability experiments with persistence forecasts in a red-noise atmosphere, Quarterly Journal of the Royal Meteorological Society, 120, 387-428, https://doi.org/10.1002/qj.49712051608, 1994. 
Freeman, A.: Facts, risks and emotions: Has journalism and science communication crossed a line?, https://medium.com/wintoncentre/ facts-risks-and-emotions-dc9db134757c, online, last accessed 22 November 2018, 2018.

Frigg, R., Thompson, E., and Werndl, C.: Philosophy of Climate Science Part I: Observing Climate Change, Philosophy Compass, 10, 953-964, https://doi.org/10.1111/phc3.12294, 2015.

5 Frisinger, H. H.: Aristole's Legacy in Meteorology, Bulletin of the American Meteorological Society, 54, 198-204, https://doi.org/10.1175/1520-0477(1973)054<0198:ALIM>2.0.CO;2, 1973.

Geographical Association and London Geographical Institute: Geographical Teacher, Bd. 1, Geographical Association., https://books.google. de/books?id=bSgiAQAAIAAJ, 1902.

Gupta, J.: The History of Global Climate Governance, Cambridge University Press, Cambridge, https://doi.org/10.1017/CBO9781139629072, 2014.

Hall, A. and Endfield, G.: "Snow Scenes": Exploring the Role of Memory and Place in Commemorating Extreme Winters, Weather, Climate, and Society, 8, 5-19, https://doi.org/10.1175/WCAS-D-15-0028.1, 2016.

Hann, J.: Handbuch der Klimatologie., Stuttgart: Engelhorn, 1883.

Heymann, M.: Klimakonstruktionen, NTM Zeitschrift für Geschichte der Wissenschaften, Technik und Medizin, 17, 171-197, https://doi.org/10.1007/s00048-009-0336-3, 2009.

Heymann, M.: The evolution of climate ideas and knowledge, Wiley Interdisciplinary Reviews: Climate Change, 1, 581-597, https://doi.org/10.1002/wcc.61, 2010.

Heymann, M.: The climate change dilemma: big science, the globalizing of climate and the loss of the human scale, Regional Environmental Change, pp. 1-12, https://doi.org/10.1007/s10113-018-1373-z, 2018.

Heymann, M. and Achermann, D.: From Climatology to Climate Science in the Twentieth Century, in: The Palgrave Handbook of Climate History, pp. 605-632, Palgrave Macmillan UK, London, https://doi.org/10.1057/978-1-137-43020-5_38, 2018.

Heymann, M., Gramelsberger, G., and Mahony, M., eds.: Cultures of prediction in atmospheric and climate science: Epistemic and cultural shifts in computer-based modelling and simulation, Routledge, https://doi.org/10.4324/9781315406282, 2017.

Hosking, J. R. M.: Modeling persistence in hydrological time series using fractional differencing, Water Resources Research, 20, 1898-1908, https://doi.org/10.1029/WR020i012p01898, 1984.

Hulme, M.: Weathered : cultures of climate, Sage, 2016.

Hulme, M., Dessai, S., Lorenzoni, I., and Nelson, D. R.: Unstable climates: Exploring the statistical and social constructions of 'normal' climate, Geoforum, 40, 197 - 206, https://doi.org/10.1016/j.geoforum.2008.09.010, themed Issue: Globalising Failures, 2009.

IPCC: Climate change 2013: the physical science basis. Contribution of working group I to the fifth assessment report of the intergovernmental panel on climate change, Cambridge University Press, 2013.

Jones, P.: The reliability of global and hemispheric surface temperature records, Advances in Atmospheric Sciences, 33, 269-282, 2016.

Katzav, J. and Parker, W. S.: Issues in the theoretical foundations of climate science, Studies in History and Philosophy of Science Part B: Studies in History and Philosophy of Modern Physics, 63, 141-149, https://doi.org/10.1016/J.SHPSB.2018.02.001, 2018.

Kennedy, J.: Practically speaking: weather's how you choose an outfit, climate's how you choose your wardrobe., https://twitter.com/ micefearboggis/status/287933033628180480, retrieved from Twitter, last accessed 21 December 2016, 2013.

Klein, R.: Scale-Dependent Models for Atmospheric Flows, Annual Review of Fluid Mechanics, 42, 249-274, https://doi.org/10.1146/annurev-fluid-121108-145537, 2010.

Version of doi:10.5194/gc-2018-11 that was rejected after one iteration of major revisions and submitted to EarthArXiv. 
Kloster, S., Feichter, J., Maier-Reimer, E., Six, K. D., Stier, P., and Wetzel, P.: DMS cycle in the marine ocean-atmosphere system - a global model study, Biogeosciences, 3, 29-51, https://doi.org/10.5194/bg-3-29-2006, 2006.

Köhler, P., Hartmann, J., and Wolf-Gladrow, D. A.: Geoengineering potential of artificially enhanced silicate weathering of olivine, Proceedings of the National Academy of Sciences, 107, 20 228-20 233, https://doi.org/10.1073/pnas.1000545107, 2010.

5 Kraus, H.: Was ist Klima?, Erdkunde, 38, https://doi.org/10.3112/erdkunde.1984.04.01, 1984.

Kraus, H.: Die Atmosphäre der Erde: Eine Einführung in die Meteorologie, Springer Berlin Heidelberg, https://books.google.de/books?id= 2RIIBgAAQBAJ, 2007.

Kravitz, B.: Designer climates?, https://geoengineering.environment.harvard.edu/blog/designer-climates, online, last accessed 22 November 2018,2018

10 Krüger, O. and Graß1, H.: Southern Ocean phytoplankton increases cloud albedo and reduces precipitation, Geophysical Research Letters, 38, L08 809, https://doi.org/10.1029/2011GL047116, 108809, 2011.

Kutzbach, J. E.: The nature of climate and climatic variations, Quaternary Research, 6, 471 - 480, https://doi.org/10.1016/00335894(76)90020-X, 1976.

Köppen, W.: The thermal zones of the Earth according to the duration of hot, moderate and cold periods and to the impact of heat on the organic world, Meteorologische Zeitschrift, 20, 351-360, https://doi.org/10.1127/0941-2948/2011/105, 2011.

Laing, A. and Evans, J.-L.: Introduction to Tropical Meteorology - A Comprehensive Online \& Print Textbook, Version 2.0, October 2011, http://www.goes-r.gov/users/comet/tropical/textbook_2nd_edition/index.htm, accessed 12 February 2016, 2011.

Lawhead, J.: Structural Modeling Error and the System Individuation Problem, http://philsci-archive.pitt.edu/11971/, 2015.

Leith, C. E.: Predictability of climate, Nature, 276, 352-355, https://doi.org/10.1038/276352a0, 1978.

Lo, Y. T. E., Charlton-Perez, A. J., Highwood, E. J., and Lott, F. C.: Best scale for detecting the effects of stratospheric sulphate aerosol geoengineering on surface temperature, Earth's Future, https://doi.org/10.1029/2018EF000933, 2018.

Lorenz, E. N.: The predictability of a flow which possesses many scales of motion, Tellus, 21, 289-307, https://doi.org/10.1111/j.21533490.1969.tb00444.x, 1969a.

Lorenz, E. N.: Three approaches to atmospheric predictability, Bull. Amer. Meteor. Soc, 50, 349, $1969 \mathrm{~b}$.

Lorenz, E. N.: On the Existence of Extended Range Predictability, Journal of Applied Meteorology, 12, 543-546, https://doi.org/10.1175/1520-0450(1973)012<0543:OTEOER>2.0.CO;2, 1973.

Lorenz, E. N.: Climate is what you expect, unpublished, available from http://eaps4.mit.edu/research/Lorenz/Climate_expect.pdf, unpublished.

Lovejoy, S.: What Is Climate?, Eos, Transactions American Geophysical Union, 94, 1-2, https://doi.org/10.1002/2013EO010001, 2013.

Lovejoy, S. and Schertzer, D.: The climate is not what you expect, http://www.physics.mcgill.ca/ gang/eprints/eprintLovejoy/esubmissions/ climate.not.19.10.12.pdf, unpublished, URL last accessed 21 December 2016, 2013.

Lovejoy, S., Schertzer, D., and Varon, D.: Do GCMs predict the climate ... or macroweather?, Earth System Dynamics, 4, 439-454, https://doi.org/10.5194/esd-4-439-2013, 2013.

Lucarini, V.: Towards a definition of climate science, Int. J. Environment and Pollution, 18, 413-422, 2002.

Mahony, M.: The (re)emergence of regional climate: Mobile models, regional visions and the government of climate change Martin Mahony, in: Cultures of Prediction in Atmospheric and Climate Science: Epistemic and Cultural Shifts in Computer-based Modelling and Simulation, Routledge, https://doi.org/10.4324/9781315406282, 2017.

Version of doi:10.5194/gc-2018-11 that was rejected after one iteration of major revisions and submitted to EarthArXiv. 
Mahony, M. and Endfield, G.: Climate and colonialism, Wiley Interdisciplinary Reviews: Climate Change, 9, e510, https://doi.org/10.1002/wcc.510, 2018.

Martin-Nielsen, J.: A new climate Hubert H. Lamb and boundary work at the UK Meteorological Office, in: Cultures of Prediction in Atmospheric and Climate Science: Epistemic and Cultural Shifts in Computer-based Modelling and Simulation, Routledge, https://doi.org/10.4324/9781315406282-13, 2017.

Mauelshagen, F.: Climate as a Scientific Paradigm_Early History of Climatology to 1800, in: The Palgrave Handbook of Climate History, pp. 565-588, Palgrave Macmillan UK, London, https://doi.org/10.1057/978-1-137-43020-5_36, 2018.

McBean, G., Golitsyn, G., and Sanhueza, E.: Atmosphere and climate, in: An Agenda of science for environment and development into the 21st century: based on a conference held in Vienna, Austria in November 1991, p. 141, Cambridge Univ Press, 1992.

10 Miller, C. and Edwards, P.: Changing the Atmosphere: Expert Knowledge and Environmental Governance, Politics, science, and the environment, MIT Press, https://books.google.de/books?id=htulve5KkQMC, 2001.

Miller, C. A.: Climate science and the making of a global political order, in: States of Knowledge - The Co-Production of Science and the Social Order, edited by Jasanoff, S., pp. 57-77, Routledge, https://doi.org/10.4324/9780203413845-8, 2004.

Mitchell, J.: An overview of climatic variability and its causal mechanisms, Quaternary Research, 6, 481-493, https://doi.org/10.1016/00335894(76)90021-1, 1976.

Mölders, N. and Kramm, G.: Lectures in Meteorology, Springer International Publishing, Cham, https://doi.org/10.1007/978-3-319-02144-7, 2014.

Moldwin, M.: An Introduction to Space Weather, Cambridge University Press, https://books.google.de/books?id=kH6aGO74YuAC, 2008.

Molua, E. and Lambi, C.: The Economic Impact Of Climate Change On Agriculture In Cameroon, The World Bank, https://doi.org/10.1596/1813-9450-4364, 2007.

Morice, C. P., Kennedy, J. J., Rayner, N. A., and Jones, P. D.: Quantifying uncertainties in global and regional temperature change using an ensemble of observational estimates: The HadCRUT4 data set, Journal of Geophysical Research: Atmospheres, 117, D08 101, https://doi.org/10.1029/2011JD017187, d08101, 2012.

Norbury, J. and Roulstone, I.: Large-Scale Atmosphere-Ocean Dynamics: Volume 1: Analytical Methods and Numerical Models, Large-scale Atmosphere-ocean Dynamics, Cambridge University Press, https://books.google.de/books?id=CRD6VONGtUkC, 2002.

Orlanski, I.: A rational subdivision of scales for atmospheric processes, Bulletin of the American Meteorological Society, 56, 527-530, 1975.

Osborn, T.: I view climate as the process that generates the weather we observe. As a process it might be described as a physical process or as a statistical process, but either way we don't get weather without the climate process to generate it, https://twitter.com/TimOsbornClim/ status/1050303279312396288, retrieved from Twitter, last accessed 26 October 2018, 2018.

Parker, W.: Climate Change, in: Philosophy of social science: A new introduction, edited by Cartwright, N. and Montuschi, E., pp. 31-47, Oxford University Press, 2014.

Parker, W. S.: Understanding Pluralism in Climate Modeling, Foundations of Science, 11, 349-368, https://doi.org/10.1007/s10699-0053196-x, 2006.

Petersen, A. C.: Philosophy of Climate Science, Bulletin of the American Meteorological Society, 81, 265-271, https://doi.org/10.1175/15200477(2000)081<0265:POCS>2.3.CO;2, 2000.

Philander, S.: El Nino, La Nina, and the Southern Oscillation, International Geophysics, Elsevier Science, https://books.google.de/books? id=9fwrkW_B1YYC, 1989. 
Prokopy, L. S., Morton, L. W., Arbuckle, J. G., Mase, A. S., Wilke, A. K., Prokopy, L. S., Morton, L. W., Jr., J. G. A., Mase, A. S., and Wilke, A. K.: Agricultural Stakeholder Views on Climate Change: Implications for Conducting Research and Outreach, Bulletin of the American Meteorological Society, 96, 181-190, https://doi.org/10.1175/BAMS-D-13-00172.1, 2015.

Quinlan, F. T.: Comments on "Sahel: The Changing Rainfall Regime and the "Normals' Used for its Assessment”, Journal of Climate and Applied Meteorology, 25, 257-257, https://doi.org/10.1175/1520-0450(1986)025<0257:COTCRR>2.0.CO;2, 1986.

Rauser, F., Gleckler, P., and Marotzke, J.: Rethinking the Default Construction of Multimodel Climate Ensembles, Bulletin of the American Meteorological Society, 96, 911-919, https://doi.org/10.1175/BAMS-D-13-00181.1, 10.1175/BAMS-D-13-00181.1, 2015.

Roe, G.: Feedbacks, Timescales, and Seeing Red, Annual Review of Earth and Planetary Sciences, 37, 93-115, https://doi.org/10.1146/annurev.earth.061008.134734, 2009.

10 Roe, G. H. and O'Neal, M. A.: The response of glaciers to intrinsic climate variability: observations and models of late-Holocene variations in the Pacific Northwest, Journal of Glaciology, 55, 839-854, https://doi.org/10.3189/002214309790152438, 2009.

Rudiak-Gould, P.: Promiscuous corroboration and climate change translation: A case study from the Marshall Islands, Global Environmental Change, 22, 46-54, https://doi.org/10.1016/J.GLOENVCHA.2011.09.011, 2012.

Schneider, S. H. and Dickinson, R. E.: Climate modeling, Reviews of Geophysics, 12, 447, https://doi.org/10.1029/RG012i003p00447, 1974.

Stehr, N. and von Storch, H.: The social construct of climate and climate change, Climate Research, 5, 99-105, https://doi.org/10.3354/cr005099, 1995.

Stehr, N. and von Storch, H.: Climate Determines: An Anatomy of a Disbanded Line of Research, http://www.hvonstorch.de/klima/pdf/ Climate.determines.pdf, unpublished, 1998.

Stehr, N. and von Storch, H.: Von der Macht des Klimas: Ist der Klimadeterminismus nur noch Ideengeschichte oder relevanter Faktor gegenwärtiger Klimapolitik?, GAIA-Ecological Perspectives for Science and Society, 9, 187-195, in German, 2000.

Stevenson, A.: Oxford Dictionary of English, Oxford Dictionary of English, OUP Oxford, https://books.google.de/books?id= anecAQAAQBAJ, 2010.

Stull, R.: An Introduction to Boundary Layer Meteorology, Atmospheric and Oceanographic Sciences Library, Springer Netherlands, https: //books.google.de/books?id=2PjrCAAAQBAJ, 2012.

Swart, N. C., Fyfe, J. C., Hawkins, E., Kay, J. E., and Jahn, A.: Influence of internal variability on Arctic sea-ice trends, Nature Clim. Change, 5, 86-89, https://doi.org/10.1038/nclimate2483 10.1038/nclimate2483, 2015.

Todorov, A. V.: Reply, Journal of Climate and Applied Meteorology, 25, 258-259, https://doi.org/10.1175/15200450(1986)025<0258:R>2.0.CO;2, 1986.

Tol, R.: I happen to think that weather is a physical reality while climate is a human artifact, but I see that that opinion is not universally shared., https://twitter.com/RichardTol/status/1050301521349550083, retrieved from Twitter, last accessed 26 October $2018,2018$.

Tourangeau, W., Sherren, K., Kent, C., MacDonald, B. H., Tourangeau, W., Sherren, K., Kent, C., and MacDonald, B. H.: Of Climate and Weather: Examining Canadian Farm and Livestock Organization Discourses from 2010 to 2015, Weather, Climate, and Society, 11, 95-111, https://doi.org/10.1175/WCAS-D-18-0028.1, 2019.

von Storch, H.: Misuses of Statistical Analysis in Climate Research, in: Analysis of Climate Variability: Applications of Statistical Techniques

Proceedings of an Autumn School Organized by the Commission of the European Community on Elba from October 30 to November 6, 1993, edited by von Storch, H. and Navarra, A., pp. 11-26, Springer Berlin Heidelberg, Berlin, Heidelberg, https://doi.org/10.1007/9783-662-03744-7_2, 1999.

Version of doi:10.5194/gc-2018-11 that was rejected after one iteration of major revisions and submitted to EarthArXiv. 
von Storch, H.: A Discourse About Quasi-realistic Climate Models and Their Applications in Paleoclimatic Studies, in: The Climate in Historical Times: Towards a Synthesis of Holocene Proxy Data and Climate Models, edited by Fischer, H., Kumke, T., Lohmann, G., Flöser, G., Miller, H., Storch, H., and Negendank, J. F. W., pp. 43-55, Springer Berlin Heidelberg, Berlin, Heidelberg, https://doi.org/10.1007/9783-662-10313-5_3, 2004.

5 von Storch, H. and Zwiers, F. W.: Statistical analysis in climate research, Cambridge University Press, 2001.

Wanner, H.: Die angewandte Geländeklimatologie - ein aktuelles Arbeitsgebiet der physischen Geographie, ERDKUNDE, 40, https://doi.org/10.3112/erdkunde.1986.01.01, 1986.

Werndl, C.: On Defining Climate and Climate Change, The British Journal for the Philosophy of Science, https://doi.org/10.1093/bjps/axu048, 2015.

10 Wiktionary: state - Wiktionary, the free dictionary, https://en.wiktionary.org/wiki/state, online, accessed 12 February $2016,2016$.

Wilbanks, T. J. and Kates, R. W.: Global Change in Local Places: How Scale Matters, Climatic Change, 43, 601-628, https://doi.org/10.1023/A:1005418924748, 1999.

Willett, H. C.: Ground Plan of A Dynamic Meteorology, Monthly Weather Review, 59, 219-223, https://doi.org/10.1175/15200493(1931)59<219:GPOADM>2.0.CO;2, 10.1175/1520-0493(1931)59<219:GPOADM>2.0.CO;2, 1931.

15 Winsberg, E.: Science in the Age of Computer Simulation, University of Chicago Press, https://doi.org/10.7208/chicago/9780226902050.001.0001, 2010.

Winsberg, E.: Philosophy and Climate Science, Cambridge University Press, https://doi.org/10.1017/9781108164290, 2018.

Zhang, C.: Madden-Julian Oscillation, Reviews of Geophysics, 43, RG2003, https://doi.org/10.1029/2004RG000158, rG2003, 2005. 